\title{
BIOPSYCHOSOCIAL-SPIRITUAL MODEL OF COVID-19 FOR HEALTHCARE PRACTITIONERS AMIDST AND POST-COVID-19
}

\author{
Sonia Mukhtar ${ }^{1,2}$ \& Waleed Rana ${ }^{3}$ \\ ${ }^{1}$ University of Management and Technology, Lahore, Pakistan \\ ${ }^{2}$ Dulwich Center, Adelaide, Australia \\ ${ }^{3}$ Hainan Medical University, Haikou, China
}

received: 4.6.2021;

revised: 19.9.2021;

accepted: 5.10 .2021

\begin{abstract}
SUMMARY
It can spread from one person to another, is contagious, independent of physical contact, and extremely dangerous - its fear. This review evaluates and examines the distinction between COVID-19 and fear of COVID-19, biopsychosocial-spiritual model of Coronavirus-related anxiety, internalization and externalization of consequential psychological issues. It further offer facilitation of health care practitioners' uniqueness in offering short-term and long-term support for psychosocial, emotional, cognitive, behavioral and mental health repercussions of COVID-19 on individual and community level.
\end{abstract}

Key words: COVID-19-fear - anxiety - mental health - psychological wellbeing - biopsychosocial-spiritual model

$* * * * *$

\section{INTRODUCTION}

COVID-19 (Coronavirus Disease 2019) outbreak which started at the end of 2019 has affected and claimed lives across countries and territories. Many systems are on the brink of collapse - indiscriminately affecting political, social, cultural, educational, socioeconomic, environment and climate, human rights, and healthcare systems. Not only the cases are increasing but the mental health consequences are exacerbating exponentially as well (Wang et al. 2020, Ren \& Guo 2020). Despite World Health Organization (WHO), Centre for Disease Control and Prevention (CDC) and National Institutes of Health's (NIH) information packages, people are drawn towards misinfodemics out of mistrust in the legitimized health systems further inciting anxiety and fear. Apart from casualties, economic loss, restriction to travel and tourism, burden of stringent complete lockdown quarantine, surplus of misinfodemics which fuels the stereotypes and stigmatization, a secondary trauma has emerged: mental health issues.

\section{COVID-19 - A MENTAL HEALTH PHENOMENON!}

Coronavirus is not merely a medical phenomenon anymore; it has become a mental-health phenomenon! Coronavirus (COVID-19) mental health problems or biopsychosocial consequences should be addressed as such. It has impacted quality of life, and social functioning of the community which are basic tenants of collectivistic cultural communities whose social functioning and quality of life are disproportionally correlated to each other. Mental health issues like posttraumatic symptoms, depressive symptoms, fear, anxiety, panic, anger, and frustration in healthcare workers (doctors, nurses, administrative staff, allied health professionals, hospital support staff [paramedics, technician, clerical, food service staff, IT and environmental service staff, janitors, cleaning, and guards]), volunteers, social service personnel, and general public factors are prevalent (Mukhtar 2020). Despite all these repercussions, lack of sensitization and awareness towards information of mental health in community is insubstantial (Chen et al. 2020). In this scenario, counselling psychologists can play a significant role towards the survivors of the disease outbreak (affected/infected/suspected/ at-risk) individuals, families and general public.

\section{CORONAVIRUS VS. FEAR OF CORONAVIRUS}

It can spread from one person to another, is contagious, independent of physical contact, and extremely dangerous - its fear. The recent outbreak of COVID-19 across all continents, countries and communities has also witnessed the upsurge of fear and panic as the byproduct of unpredictability and uncertainty. The impact lies in the magnitude, adversity, severity, intensity, novelty, frequency and uncertainty of such scale which has shaken the individual and collective sense of safety, security, stability and solidarity.

As the COVID-19 proliferates two phenomena are largely at play: there is a pandemic of coronavirus and then there is a pandemic of the fear of coronavirus. Experts have advised self-isolation, social-distancing, and quarantine over coronavirus contagion; print and electronic media has publicized coronavirus panic shopping and hoarding; internet has exposed the attacks against Asians sparked by xenophobic stereotyped coronavirus fears - 
subsequently spreading panic and fear faster than coronavirus. Adding to fuel are internet's conspiracy theories driven by personal or political twisted motives bent on perpetuating misinformation and misconceptions. Fashioning conspiracy theories is a function of unsupported inexplicable set of stories which provide a tentative personal opinion presented as factual reasoning (Mukhtar 2021).

\section{INTERNALIZING PROBLEMS: 'AM I IMMUNE TO CORONAVIRUS?'}

Many communities and cultures concoct their own sense of explanation of the events, like specific practices prevents 'evil', some food items cures diseases, reading certain words avert the sickness and the very notion that certain people are exempted from contracting coronavirus ("we are immune to coronavirus"). Science, however, is a systematic enterprise of testable (consistent and repeated), rational (logically proof and positive evidence) and factual (completely substantiated) explanations of events. Everything beyond the premise of science falls under the category of 'nonscience'. These mythical, miraculous, magical and mysterious conspiracy stories are all which science is not attractive, baseless, farfetched and magically plausible.

These conspiracy stories are Contradicting, Orchestrated/Ostentatious, Negative, Scandalous, Perjured, Insinuated, Random and Euphemistic. Partiality towards these stories lies in the illusion of certainty, wishful thinking, and unquestionable conformity of norms. It poses difficulty in spotting misinformation online because of an un-invested time to fact-check or actively seeking information that validates preexisting beliefs and elicit strong emotions. The psychological states triggered by rapid, unanticipated, and frightening experiences can often lead to the clouded judgment by bias, prejudice, discrimination, irrational attitudes, stigma and marginalization ascribing to the cause of the problem.

\section{EXTERNALIZING PROBLEMS: 'YOU MADE ME SICK'}

In the wake of COVID-19, numerous reports of stereotyped xenophobia directed towards Chinese are astonishing, for instance, closed Chinese restaurants, laid off Chinese employees, and Chinese people are barred from restaurants and cruise ships (Aguilera 2020, Evelyn 2020). The prime example could be the racialized rhetoric of COVID-19 as the Chinese Virus or Wuhan Virus or Kung-Flu which incited mass level discrimination, harassment and violence against Asians. Many U.S. respondents $(32 \%)$ in a poll blamed Chinese government for the COVID-19 into the United States (Marčinko et al. 2020). The infection-related social-identity xenophobia appears to be an unfortunately common response in previous pandemics. And while the exact nature and impact of COVID-19 on mental health remains to be determined, previous researches could offer expected indications on psychological reactions during epidemics and pandemics.

\section{BIOPSYCHOSOCIAL-SPIRITUAL MODEL OF COVID-19}

The anxiety of contracting and susceptibility is not only related to coronavirus but also with the embrace of false claims, and hostile attitudes towards others which in turn amplify fear and anxiety. The availability bias only accentuates self-perpetuating hampered critical thinking and decisions, and as a result people interpret events in a threatening way. Emotions could also impair the perception of assessing risk and since knowledge of COVID-19 is still evolving so uncertainty and unpredictability gives the attribution of perceived external locus of control. Corona-related anxiety could be a product of mis-calibrated emotion and mis-information.

Brains are hardwired to automatic, unconscious survival responses to threats through fight, flight, fright or freeze. This phenomenon explains mass panic attacks during public gatherings where once fear is triggered from unverified sources of terror end up with tragedies. In addition to information about socially-transferred fear, information about safety and tolerance should be delivered. During stress, details and nuances are hard to process and partial or misinformation could increase uncertainty and uncertainty augments fear and anxiety. In the end no one can control every single risk in life and live a meaningful, reasonable and productive life simultaneously.

The psychosocial-spiritual impact of COVID-19 pandemic outbreak is mediated by people's perceptions (Jakovljevic et al. 2020). COVID-19 has witnessed two seemingly prevalent psychological factors: avoidance or worry. In case of denial and avoidance possibly due to the fear of quarantine people are resisting; and people who are worried and anxious misinterpret their bodily sensations as symptoms of novel coronavirus. Many factors are contributing in the mental health, emotionalbehavioral functioning, wellbeing, resilience, coping, psychological and social wellness, psychosocial functioning, emotional welfare and quality of life including uncertainty and unpredictability of this unknown illness, lockdown measures (self-isolation, social distancing, and quarantine), interpersonal issues, social dysfunctioning, emotional and behavioral issues, psychological problems, previously existing mental health issues, or proneness of getting effected from traumatic events has perpetuated predisposing and precipitating mental health factors (Rana et al. 2020). Psychological vulnerability and individual differences such as intolerance of uncertainty, chronic anxiety and perceived vulnerability to disease plays a crucial role in corona-related anxiety (Rana et al. 2021). Similarly, misconceptions, misinformation and popular rhetoric against COVID-19 have been shown to incite fears, phobias and often violence. In that particular scenario, counselling psychologists' intervention for assessment and management of these aspects will be substantial. 


\section{MENTAL HEALTHCARE PRACTITIONERS' UNIQUENESS}

Mental Healthcare Practitioners are uniquely equipped with knowledge, expertise, experience, practice, eclectic perspective, integrative approach, cross-cultural framework, pragmatic research method, and theory-practice emulsified in a client focused approach. Counselling psychologists believe that everyone has an innate capacity to grow emotionally and psychologically towards the self-actualization and personal fulfillment. Counselling psychology is a health service provider specialty in professional psychology which focuses on in assessing, analyzing and managing how people function and addresses the emotional, mental, psychological, social, work, academic, and physical health concerns at different stages in the lies of individuals, families, groups and organizations to improve their sense of wellbeing, alleviate feelings of distress and resolves crisis. For instance, assessment, management and prevention in counselling and psychotherapy for crisis intervention, disaster, and trauma management; training programs/workshops to educate and inform people about mental health, personal and interpersonal functioning, school, family, relationships, and workplace issues; consultation with organizations; and psychometrics. Counselling psychologists' therapeutic approach lies within the belief that problems are not caused by life events but how people experience and perceive them. This experience and perception in turn affects the emotions and feelings directed inwards and influence self-constructs and wellbeing. Counselling psychologists' approach to counselling therefore encourages clients to learn to understand their responses towards their life events (which lead to psychological discomfort) and aims for clients to explore their own thoughts and feelings and to work out their own unique solutions by learning self-acceptance to both negative and positive aspects of character and personality. Given are some of the possible interventions counselling psychologists can intermediate (Table 1).

\section{NORMALIZING AND SENSITIZING PUBLIC ABOUT PSYCHOLOGICAL IMPACT}

COVID-19 as an extreme life stressor has been causing negative emotions and compromising mental wellbeing - inducing the hopelessness feeling that any effort aimed to constructive change is not futile and the helplessness notion that nothing more can be done to change the situation. In this particular case of COVID19 pandemic outbreak, likely cognitive biases are blackand-white thinking, jumping-to-conclusions, overgeneralization, minimization, magnification, personalization, abstraction and catastrophization. It is hardly surprising that challenging situations induce states of hopelessness and helplessness and an individual might think that, "We are not going to survive coronavirus" and "this is the end of the world". Such negative thoughts, unhelpful behaviors, cognitive-dissonance eventually unsettle the peace of mind so empowering skills, learning self-isolation and coping skills would help changing these thoughts and behaviors (Graham et al. 2016). Normalization and behavioral activation could challenge catastrophizing thoughts. In addition to modifying lifestyle change and stress management, mindfulness and acceptance and commitment intervention can be used to help individuals and communities foster and cultivate resilience (Padesky \& Mooney 2012).

Normalizing and sensitizing are the objectives of this interventional phase. Educating and informing people about the common psychological reactions emanated from the viral infectious disease pandemic outbreak. Common stress emotional responses like irritability, isolation, anger or worry could be evident in children and adolescents. Other psychological stress responses like fear, anxiety, panic, anger, stigma, marginalization, discrimination, and prejudice could be evident in general population. Important aspect in this situation is to educate and inform people about general measures of safeguarding mental health by counteracting mental health concerns. People should be informed about 'common and normal' stress responses which can create

Table 1. Healthcare Practitioners' blueprint of strategies for mental health planning

\begin{tabular}{|c|c|c|}
\hline & Short-term Strategies & Long-term Strategies \\
\hline Psychological Impact & $\begin{array}{l}\text { Monitoring and reporting of mental } \\
\text { health issues; reassure mental health } \\
\text { help-seeking behaviors }\end{array}$ & $\begin{array}{l}\text { Normalizing and sensitization; ascertain } \\
\text { psychosocial consequences on wellbeing }\end{array}$ \\
\hline Sound Mental Health & $\begin{array}{l}\text { Manage psychological physical and } \\
\text { organizational factors; educate } \\
\text { behavioral modification }\end{array}$ & $\begin{array}{l}\text { Protect mental wellbeing and promote } \\
\text { positive emotions; optimize community } \\
\text { collaboration }\end{array}$ \\
\hline Vulnerable groups & $\begin{array}{l}\text { Identify outreach methods and commu- } \\
\text { nity support; identify gaps in rapid } \\
\text { intervention; facilitate personal growth }\end{array}$ & $\begin{array}{l}\text { Approaches on prevention and treatment } \\
\text { of mental health symptoms; facilitate } \\
\text { self-empathy }\end{array}$ \\
\hline $\begin{array}{l}\text { Adherence to lifestyle change, } \\
\text { mental wellbeing }\end{array}$ & $\begin{array}{l}\text { Holistic empowerment of community; } \\
\text { optimize behavior change; track } \\
\text { perceptions and public responses }\end{array}$ & $\begin{array}{l}\text { Enable communities to psychological } \\
\text { preparedness for future scenario; } \\
\text { understand facilitators and barriers in } \\
\text { providing mental health services }\end{array}$ \\
\hline
\end{tabular}


a range of emotional, behavioral and psychological effects in individuals as a common occurrence which happens as a consequence of a traumatic event.

\section{EDUCATING ABOUT LIFESTYLE, BEHAVIORAL MODIFICATION AND SOCIAL LEARNING}

The general public needs to be directed to credulous sources for accurate information on social distancing, self-isolation and quarantine and countermeasures for better adherence with lockdown. Lifestyle, behavioral modification and social-learning is the key element in this situation such as hygiene, activity scheduling, nature connectedness, introspection, mindfulness, meditation, painting, reading, listening, playing, watching, learning, dancing, gardening, and connecting with family to decrease stress. Limiting the exposure of social media and spreading misinfodemics of misinformation, and disinformation to create panic is inadvisable. Constant exposure to the infectious diseases' affects through direct or indirect media exposure misinfodemics could create apprehensions of being infected and carrier of the disease which could culminate anxiety, guilt, helplessness, hopelessness, and negative emotions.

\section{PROMOTE COMMUNITY SUPPORT AND SOCIAL FACILITATION}

Counselling psychologists can play an integral role in optimizing the social-identity misconceptions (stigmatization, marginalization, stereotype, xenophobia, discrimination, prejudice, bias and misplaced negative emotions and behavioral reactions) by collaborating with the state's sanctioned legitimized organizations to offer community support. Creating sensitization and altruistic cohesive mutual support for each individual in community is one of the interventions counselling psychologists can offer to the distressed community members. Counselling psychologists' unique mental health perspectives and psychological crisis intervention approach to manage collective trauma and psychotherapeutic management provide community a sense of normalization and harmony. Cultivating the resilience, altruism, prosocial behaviors, optimism, hope, positive emotions to cope with the anxiety, loneliness, change in sleep or eating pattern, posttraumatic symptoms, emotional distress, and exacerbated physical and mental health to improve the quality of life and wellbeing. Mental health risk assessment and crisis management on individual and community measure and responses should be due diligently implemented. Counselling psychologists can offer support in the face of a mutual trauma and collective psychological distress, communities can build resilience, help each other to cope with the dire situation, manage physical and mental wellbeing, deal with personal trauma, and build strategies to prevent long-term mental and emotional behavioral health problems. Counselling psychologists could implement timely-brief empirically-evident public mental health interventions to build resilience on individual and community level (Rana et al. 2020).

\section{FACILITATE PERSONAL GROWTH AND SELF-EMPATHY}

Various self-constructs from self-efficacy, selfesteem, self-confidence, self-concept, self-image, selfidentity, self-awareness, self-knowledge, and selfconceptualization are the major factors impacted by the traumatic events and counselling psychologists' objective is to identify, ensure and manage the discrepancy in achieving these constructs to facilitate personal growth. Self-reliance and self-sufficiency should be cultivated in the wake of mandatory social-distancing, and self-isolation to foster independence and individuality. This self-isolation provides the most suited prospect of know-thyself by looking within, spending time with oneself, given own-self the unconditional positive regard by self-reflection and self-understanding and self-acceptance. Self-constructs can be reinvigorated to convert loneliness into self-reflecting isolation, hopelessness into self-assuring optimism, anxiety into selfsoothing excitement, fear into self-compassionate reinforcement and hatred into self-kindred empathy. People could practice meditation and practice mindfulness for self-relaxation and self-care to self-soothe.

\section{HOLISTIC EMPOWERMENT OF INDIVIDUALS AND COMMUNITY}

Mental health repercussions of coronavirus could have short-term and long-term effects on individuals and on community. These effects could contribute in developing adjustment issues and acute/chronic posttraumatic symptoms stemmed from perceived anxiety and fear. Ensuring the survivors of coronavirus illness including affected and suspected individuals, families, healthcare professionals, volunteer and social services personnel and general public about their mental health and physical health through holistic supportive interventions and management could facilitate adjustment, acceptance and willingness to change. In this situation, constructive support, counselling, mental health interventions, and self-care could prevent impaired functioning and improve quality of life.

\section{RESILIENCE, COPING, WELLBEING AND CHANGE}

Resilience is an individual's ability to recover readily from adversity and bounce back; and it is the community's interactive and dynamic process of adapting and regulating in adversity. Proactively nurturing 
positive emotions in individuals and communities could stimulate resilience to manage stress, boredom, loneliness, and collective change in the world. Coping with mental and psychological problems is paramount challenge in the wake of COVID-19 pandemic outbreak. Resilience could build positive emotions, healthy behaviors, healthy positive ageing, subjective quality of life, well-being (social wellbeing, emotional wellbeing, psychological wellbeing, spiritual wellbeing, and physical wellbeing), and life satisfaction. Short term training in mindfulness improved markers of resilience and collective sense of empowerment and feeling of belongings promotes resilience (Oldfield et al. 2020). Development and implication of public health level interventions to help individuals and communities to build resilience in the face of one of the most challenging situation the world has ever witnessed.

\section{CONCLUSION}

Mental health care practitioners could bring the attention of policy makers, decision makers, and governments to introduce mental health services and psychological crisis intervention for individuals and community at this crisis. Healthcare teaching approaches (educational material, experts' views, and user manuals) integrated with community base interventions could be implemented to deal with coronanxiety among anxious individuals, patients and their family, medical personnel and general public. counselling psychologists could address empirically evidence-based approaches of biopsychosocial factors including corona-related anxiety or lack of due caution, corona-related xenophobia, and stigmatization and thus indirectly contributing the healthcare system to deal with the influx of patients at hospitals whose problem is not coronavirus. Such interventions are not only important for COVID19 but also for future epidemic or pandemic outbreak of infections.

\section{Acknowledgements: None.}

\section{Conflict of interest: None to declare.}

\section{Contribution of individual authors:}

All authors contribute equally in this study.

\section{References}

1. Aguilera J: Xenophobia "is a pre-existing condition." how harmful stereotypes and racism are spreading around the coronavirus. Time. Retrieved from https://time.com/5775716/ xenophobia-racism-stereotypes-coronavirus/

2. Chen Q, Liang M, Li Y, Guo J, Fei D, Wang L, He L, Sheng C, Cai Y, Li X, Wang J. (2020). Mental health care for medical staff in China during the COVID-19 outbreak. Lancet Psychiatry 2020. doi.org/10.1016/S2215-0366(20)30078-X

3. Evelyn K. Coronavirus: Royal Caribbean bans all Chinese nationals from its cruise ships. The Guardian. Retrieved from https://www.theguardian.com/world/2020/feb/07/ coronavirus-royal-caribbean-cruise-bans-chinese-nationals

4. Graham CD, Gouick J, Krahé C, Gillanders D. A systematic review of the use of Acceptance and Commitment Therapy (ACT) in chronic disease and long-term conditions. Clin Psychol Rev 2016; 46:46-58. 10.1016/j.cpr. 2016.04.009.

5. Jakovljevic M, Bjedov S, Jaksic N, Jakovljevic I: COVID19 Pandemia and Public and Global Mental Health from the Perspective of Global Health Security. Psychiatr Danub 2020; 32:6 14

6. Marčinko D, Jakovljević M, Jakšić N, Bjedov S, Mindoljević Drakulic A: The Importance of Psychodynamic Approach During COVID-19 Pandemic. Psychiatr Danub 2020; $32: 1521$

7. Mukhtar S. Psychological health during the coronavirus disease 2019 pandemic outbreak. Int J Soc Psychiatry 2020; 66:512-516. doi:10.1177/0020764020925835

8. Mukhtar S. Psychology and politics of COVID-19 misinfodemics: Why and how do people believe in misinfodemics? Int Sociol 2021; 36:111-123. doi:10.1177/0268580920948807

9. Oldfield J, Stevenson A, Ortiz E. Promoting resilience in street connected young people in Guatemala: the role of psychological and educational protective factors $J$. Community Psychol 2020; 48 (2): 590-604

10. Padesky CA \& Mooney KA. Strengths based cognitive-behavioural therapy: a four-step model to build resilience. Clin Psychol Psychother 2012; 19:283-90. 10.1002/ cpp.1795

11. Rana W, Mukhtar S, Mukhtar S, Mohiuddin G, Ehmad A. Psychological health of aging mental healthcare social workforce amidst coronavirus disease-2019 pandemic. Int J Geriatr Psychiatry 2021; 36:461-462. https://doi.org/10.1002/gps.5456

12. Rana W, Mukhtar S, Mukhtar S. Mental health of medical workers in Pakistan during the pandemic COVID-19 outbreak. Asian J Psychiatry 2020; 51:102080. doi:10.1016/j.ajp.2020.102080

13. Ren FF, Guo RJ: Public Mental Health in Post-COVID-19 Era. Psychiatr Danub. 2020; 32:251-255

14. Wang C, Horby PW, Hayden FG, Gao GF. A novel coronavirus outbreak of global health concern. Lancet 2020; 395:470-473

\section{Correspondence:}

Waleed Rana, MD, MBBS

Hainan Medical University

Haikou, China

E-mail:waleedrana312@gmail.com 